\title{
Spinal Cord Terminations of the Medial Wall Motor Areas in Macaque Monkeys
}

\author{
Richard P. Dum ${ }^{1}$ and Peter L. Strick ${ }^{1,2}$ \\ ${ }^{1}$ Departments of Neurosurgery and Physiology, SUNY Health Science Center at Syracuse, and ${ }^{2}$ Research Service, \\ Veterans Affairs Medical Center, Syracuse, New York 13210
}

We used anterograde transport of wheat germ agglutininhorseradish peroxidase to examine the pattern of spinal termination of efferents from the supplementary motor area (SMA) and the two caudal cingulate motor areas (CMAd and CMAv). Our analysis was limited to cervical segments of the macaque. For comparison, we also examined the pattern of termination of efferents from the primary motor cortex (M1).

The SMA, CMAd, CMAv, and M1 all terminate in the ventral horn (lamina IX). Thus, all of these motor areas appear to have direct connections with spinal motoneurons, particularly those innervating muscles of the fingers and wrist. All of the motor areas also terminate in the intermediate zone of the spinal cord (laminae V-VIII). Terminations from the SMA and M1 were densest in three regions: (1) dorsolaterally within laminae V-VII; (2) dorsomedially within lamina VI; and (3) ventromedially within lamina VII and adjacent lamina VIII. In contrast, efferents from the CMAd terminate most densely in the dorsolateral portion of the intermediate zone, whereas those from the CMAv were concentrated in the dorsomedial region. Thus, the CMAd and CMAv may innervate distinct sets of interneurons that project directly to motoneurons, and thereby influence specific aspects of segmental motor control.

These results suggest that corticospinal projections from the SMA, CMAd, and CMAv are in many respects similar to those of efferents from M1. Consequently, each of the motor areas on the medial wall has the potential to generate and control movement at the level of the spinal cord and may provide an anatomical substrate for the recovery of motor function that follows damage to $\mathrm{M} 1$.

Key words: cingulate motor areas; corticospinal terminations; frontal lobe; monkey; motor control; motor cortex; pyramidal tract; spinal cord; supplementary motor area
A number of cortical motor areas have been identified on the medial wall of the hemisphere in monkeys (for review, see Dum and Strick, 1991b; He et al., 1995). These include the supplementary motor area (SMA) and two cingulate motor areas located caudally on the dorsal and ventral banks of the cingulate sulcus (CMAd and CMAv). Each of these motor areas contains a substantial number of neurons that project to the spinal cord (Catsman-Berrevoets and Kuypers, 1976; Biber et al., 1978; Murray and Coulter, 1981; Macpherson et al., 1982; Toyoshima and Sakai, 1982; Hutchins et al., 1988; Keizer and Kuypers, 1989; Nudo and Masterton, 1990; Dum and Strick, 1991a,b; Galea and Darian-Smith, 1994; He et al., 1995). Consequently, the medial wall motor areas have the potential to influence spinal cord mechanisms via pathways that are independent of the primary motor cortex (M1).

The pattern of spinal termination of efferents from a cortical area provides a clear indication of its potential influence on spinal mechanisms. For example, efferents from M1 are known to terminate most densely in the intermediate zone of the spinal cord (laminae V-VIII) and in portions of the ventral horn (Kuypers, 1960; Liu and Chambers, 1964; Kuypers and Brinkman, 1970; Cheema et al., 1984; Ralston and Ralston, 1985; Bortoff and

\footnotetext{
Received May 15, 1996; revised July 24, 1996; accepted July 26, 1996.

This work was supported by the Veterans Affairs Medical Research Service and Rehabilitation Research and Development Service, and by U.S. Public Health Service Grant 24328 (P.L.S.). We thank Mike Page for the development of computer programs and Michele Corneille, Sarah Fitzpatrick, and Karen Hughes for their expert technical assistance.

Correspondence should be addressed to Dr. Peter L. Strick, Research Service (151S), Veterans Affairs Medical Center, Syracuse, NY 13210.

Copyright (C) 1996 Society for Neuroscience $0270-6474 / 96 / 166513-13 \$ 05.00 / 0$
}

Strick, 1993). Some of the terminations in the ventral horn are known to connect directly with motoneurons (for review, see Porter and Lemon, 1993). This connection has been regarded as essential for the generation of relatively independent finger movements and precision grip (Lawrence and Kuypers, 1968; Heffner and Masterton, 1975; Bortoff and Strick, 1993) (for review, see Kuypers, 1981). In contrast, corticospinal efferents from the primary somatosensory cortex tend to terminate most densely in the dorsal horn of the spinal cord (Liu and Chambers, 1964; Coulter and Jones, 1977; Cheema et al., 1984; Ralston and Ralston, 1985). These terminations appear to be concerned primarily with aspects of sensory processing and may modulate the flow of ascending sensory information (Yezierski et al., 1983) (for review, see Porter and Lemon, 1993).

To date, only brief and somewhat conflicting reports have appeared concerning the site of termination of efferents from the SMA (DeVito and Smith, 1959; Brinkman, 1982; Cheema et al., 1983), and no full reports have been published on the site of spinal termination of efferents from the CMAd and CMAv (Dum and Strick, 1995, 1996). Thus, the objective of the present experiments was twofold: (1) to determine the patterns of termination of efferents from the "arm" representations of the SMA, CMAd, and CMAv within cervical segments of the spinal cord and (2) to compare these patterns with that of M1.

Some of these results have been reported in preliminary form (Dum and Strick, 1993, 1995, 1996).

\section{MATERIALS AND METHODS}

The present study is based on observations from five pig-tailed (Macaca nemestrina, 4.3-13.8 kg) and two rhesus monkeys (Macaca mulatta, 8.6$11.9 \mathrm{~kg}$ ). These animals received injections of wheat germ agglutinin- 


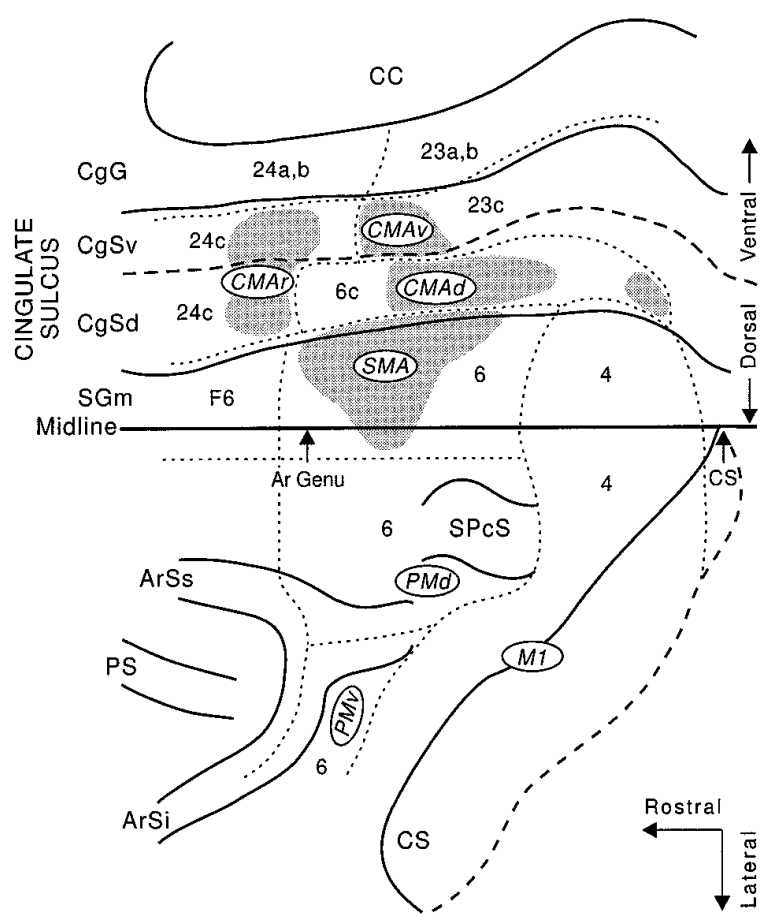

Figure 1. Origin of corticospinal projections from the motor areas on the medial wall of the hemisphere. This reconstruction of the frontal lobe of a macaque brain indicates the origin of corticospinal neurons (shaded regions) that project to the cervical segments of the spinal cord. In this view, the medial wall is unfolded and reflected upward to reveal the cingulate sulcus. The anterior bank of the central sulcus is also unfolded. A dashed line marks the fundus of each unfolded sulcus. The centers of the different cortical motor areas are designated by the circled letters. The boundaries between the motor areas and cytoarchitectonic areas (identified by numbers) are denoted with dotted lines. Ar Genu (with arrow), Level of the genu of the arcuate sulcus; $\mathrm{ArSi}$, inferior limb of the arcuate sulcus; $A r S s$, superior limb of the arcuate sulcus; $C C$, corpus callosum; $C g G$, cingulate gyrus; $C g S d$, dorsal bank of the cingulate sulcus; $C g S v$, ventral bank of the cingulate sulcus; $C M A d$, cingulate motor area on the dorsal bank of the cingulate sulcus; $C M A r$, rostral cingulate motor area; $C M A v$, cingulate motor area on the ventral bank of the cingulate sulcus; $C S$, central sulcus; $M 1$, primary motor cortex; $P M d$, dorsal premotor area; $P M v$, ventral premotor area; $P S$, principal sulcus; $S G m$, medial portion of the superior frontal gyrus; $S P C S$, superior precentral sulcus; $S M A$, supplementary motor area. Adapted from Dum and Strick (1991b).

horseradish peroxidase (WGA-HRP) into the SMA $(n=2)$, the CMAd $(n=1)$, CMAv $(n=1)$, the M1 $(n=1)$, and into both the CMAd and the CMAv $(n=2)$. The surgical, histological, and analytical procedures that we used to study these animals are quite similar to those presented in a previous publication (Bortoff and Strick, 1993) and will only be reviewed briefly here. The use of animals in this study followed the principles approved by the U.S. Public Health Service policy on Humane Care and Use of Laboratory Animals and National Institutes of Health Guide for the Care and Use of Laboratory Animals.

The target of our tracer injections was the "arm" representation in each motor area (Fig. 1) (Dum and Strick, 1991a,b; He et al., 1993, 1995). The location of an injection site was based on the surface topography and sulcal patterns of each monkey. In addition, the appropriate angles and depths for injections into the cingulate sulcus were determined from magnetic resonance images (2.0 Tesla, coronal slices, $2 \mathrm{~mm}$ thick, GECSI Imaging Spectroscopy System) acquired $\sim 1$ week before surgery. To acquire these images, animals were anesthetized with Telazol (5-10 $\mathrm{mg} \cdot \mathrm{kg}^{-1} \cdot \mathrm{hr}^{-1}$, i.m.) (Schobert, 1987) and treated with atropine $(0.05$ $\mathrm{mg} / \mathrm{kg}$, i.m.).

\section{Surgical procedures}

One day before surgery, each animal was treated with dexamethasone $(0.5 \mathrm{mg} / \mathrm{kg}$, i.m. $)$. Access to food and water was restricted $12 \mathrm{hr}$ before surgery. The animals were anesthetized with Telazol $\left(5-10 \mathrm{mg} \cdot \mathrm{kg}^{-1} \cdot \mathrm{hr}^{-1}\right.$, i.m.) or isoflurane. When Telazol was used, a complementary analgesic (Torbugesic, $0.1-0.4 \mathrm{mg} / \mathrm{kg}$, i.m.) was given to reduce the amount of anesthetic. When anesthetized, each animal received atropine $(0.05 \mathrm{mg} / \mathrm{kg}$, i.m. $)$, an antibiotic (Rocephin, $75 \mathrm{mg} / \mathrm{kg}$, i.m.), dexamethasone, and IV fluids (10-20 cc/hr during surgery). Vital signs were monitored, and body temperature was maintained between 37 and $38^{\circ} \mathrm{C}$.

All surgical procedures were performed using sterile techniques. The animal's head was held in a stereotaxic apparatus, and a large craniotomy was performed over the appropriate brain region. The dura was opened and multiple sites in the appropriate cortical region were injected with WGA-HRP $(0.05 \mu \mathrm{l}$ per site, 2 or $10 \%$ dissolved in $0.5 \mathrm{M} \mathrm{NaCl}$ with 0.1 M mannose) using a $5 \mu \mathrm{l}$ Hamilton syringe. To inject the SMA, one hemisphere was gently retracted, and the bent needle $\left(90^{\circ}\right.$ angle) of a syringe was inserted horizontally $1.5 \mathrm{~mm}$ below the pial surface into the superior frontal gyrus of the opposite hemisphere (Fig. 1B). Penetrations were spaced $1.5 \mathrm{~mm}$ apart except to avoid surface blood vessels. Injections into the CMAd or the CMAv were made in the same manner except that multiple deposits of tracer were placed at different depths along the dorsal or ventral banks of the cingulate sulcus. In two animals, access to the cingulate sulcus was facilitated by transection of the corpus callosum. To inject M1, one row of penetrations was made into the cortex in the anterior bank of the central sulcus. Tracer was injected 4.5, 3.0, and 1.5 $\mathrm{mm}$ below the surface. Then, a second row of penetrations was placed more anteriorly into cortex on the precentral gyrus, and tracer was injected $1.5 \mathrm{~mm}$ below the surface. After each injection, the needle was left in place for 1-3 min. After the last injection, the dura was covered with surgical-grade SILASTIC, the bone flap was replaced, and the wound was closed in anatomical layers. An analgesic (Torbugesic, 0.1-0.4 $\mathrm{mg} / \mathrm{kg}$, i.m.) was given at the end of surgery to ease recovery and at subsequent times if the animal exhibited discomfort. The animal was returned to its home cage, and its recovery was carefully monitored.

\section{Histological processing}

After a 4-5 d survival period, each animal was anesthetized (ketamine, 20 $\mathrm{mg} / \mathrm{kg}$, i.m.; Nembutal, $36 \mathrm{mg} / \mathrm{kg}$, i.p.) and perfused transcardially using a multiple-stage procedure (Rosene and Mesulam, 1978; Mesulam, 1982). The perfusates included: (1) $0.1 \mathrm{~m}$ phosphate buffer, $\mathrm{pH} 7.4$; (2) $3 \%$ paraformaldehyde in $0.1 \mathrm{M}$ phosphate buffer; (3) $3 \%$ paraformaldehyde in $0.1 \mathrm{M}$ phosphate buffer with $10 \%$ glycerin; (4) $0.1 \mathrm{M}$ phosphate buffer with $10 \%$ glycerin. After the perfusion, the brain and spinal cord were stored at $4^{\circ} \mathrm{C}$ in buffered $20 \%$ glycerin (Rosene et al., 1986).

The segmental levels of the spinal cord (Hartman and Straus, 1933; Hill, 1974) were marked by placing a small injection of India ink into the ipsilateral spinal cord at the junctions of dorsal root entry zones. Serial sections $(50 \mu \mathrm{m})$ of the spinal cord blocks $(\mathrm{C} 2-\mathrm{C} 5, \mathrm{C} 6-\mathrm{T} 2)$ and the brain block containing the cortical injection sites were cut on a freezing microtome. Every tenth section was processed for cytoarchitecture using Nissl stain (Mesulam, 1982). The remaining sections were processed for HRP using tetramethylbenzidine (TMB) as the substrate (Mesulam, 1982; Gibson et al., 1984) and mounted on subbed slides.

\section{Analytical procedures}

The outlines of sections and the locations of injection sites, labeled processes, and tissue landmarks (e.g., blood vessels, spinal lamina, cortical cytoarchitecture) were plotted and stored using a computerized charting system (Minnesota Datametrics). This system uses optical encoders to sense $x-y$ movements of the microscope stage and stores the coordinates of charted structures on an IBM-compatible computer.

Injection site analysis. The regions from which neurons incorporate and transport WGA-HRP cannot be determined with precision (Mesulam, 1982). We have followed the current convention and considered the injection site to include the densely stained region adjacent to each needle track (Fig. 2), but not the surrounding region with background staining where individual neurons could be distinguished (Mesulam, 1982). We mapped the location of injection sites using custom computer programs that create unfolded maps of the cortical surface (Dum and Strick, 1991b; He et al., 1993, 1995).

Determination of spinal laminae. Laminar borders were drawn on the captured images of labeled spinal cord sections with a computer drawing program. To visualize cell bodies and white matter in these sections, we adjusted the microscope condenser, dark-field ring, and polarizer to create quasi-phase conditions. Then, we determined the laminar borders using adjacent Nissl-stained sections of the spinal cord and published criteria as guides (Fig. 3) (Rexed, 1952; Apkarian and Hodge, 1989). 

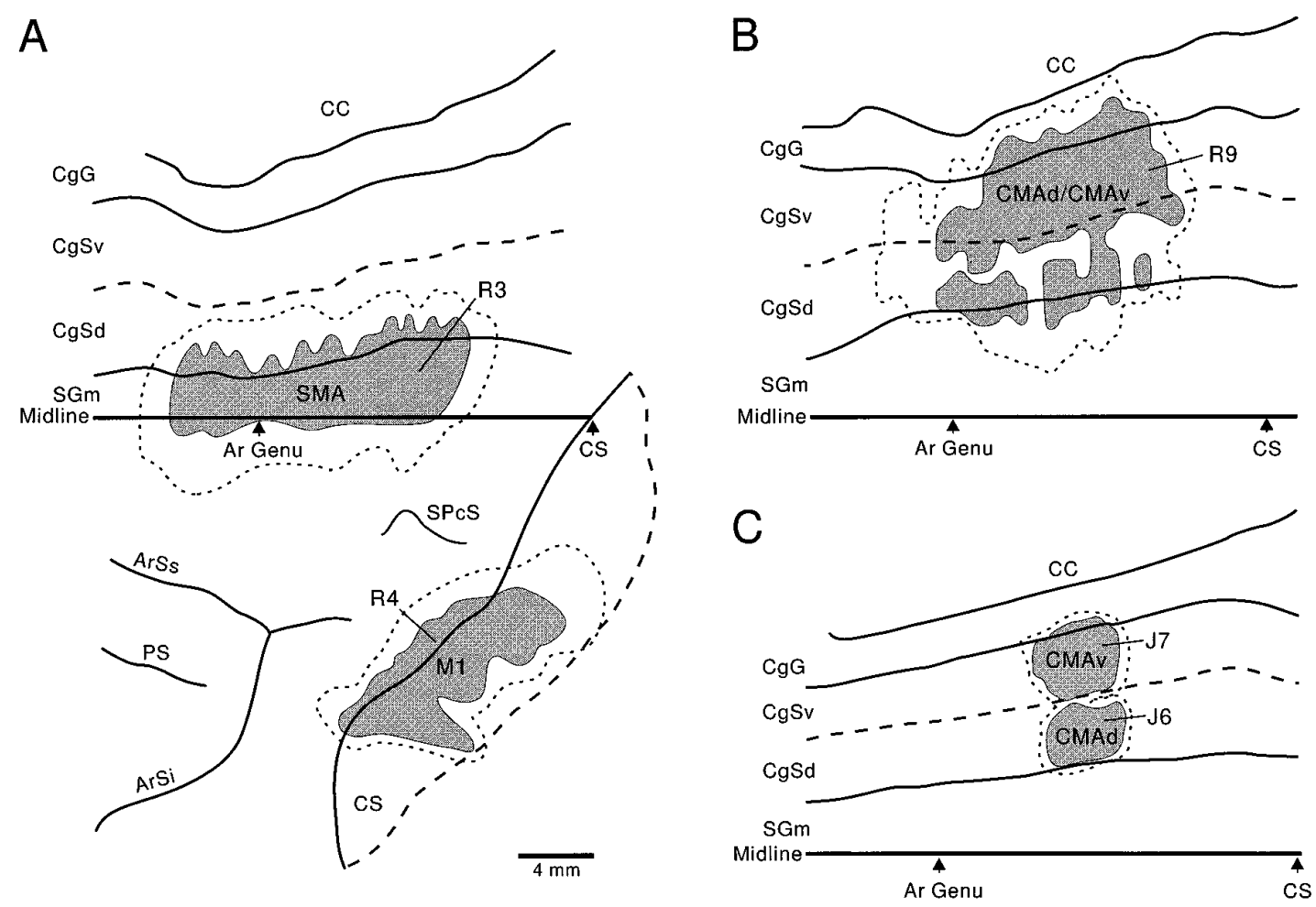

Figure 2. Location of cortical injection sites. $A$, Injection sites in the SMA (animal $R 3$ ) and M1 (animal R4) are illustrated on a map of the frontal lobe. $B$, Injection site involving both the CMAd and the CMAv (animal $R 9$ ). $C$, The injection sites in the CMAd (animal $J 6$ ) and the CMAv (animal $J 7$ ) are shown on a single map of the medial wall. The dense core of reaction product (shaded region) at each injection site was considered to be the site of uptake and anterograde transport. The dotted line surrounding each dense core indicates the surrounding region with heavily labeled neurons and strong background labeling. Calibration in $A$ applies to all maps. For conventions and abbreviations, see Figure 1.

Analysis of spinal terminations. We performed a gradient density analysis to quantitatively analyze WGA-HRP reaction product indicative of anterograde transport. Individual sections were viewed under dark-field illumination with polarized light and captured using a Newvicon video camera (Dage-MTI Series 68) coupled to an image capture board (Imaging Technologies) in an IBM-compatible computer. Images were captured at a magnification that resulted in pixels measuring $4.8 \times 5.7 \mu \mathrm{m}$. Adjacent sections stained with cresyl violet were then examined under bright-field illumination, and the boundaries of spinal laminae (Rexed, 1952) were added to the images using an interactive computer drawing program.

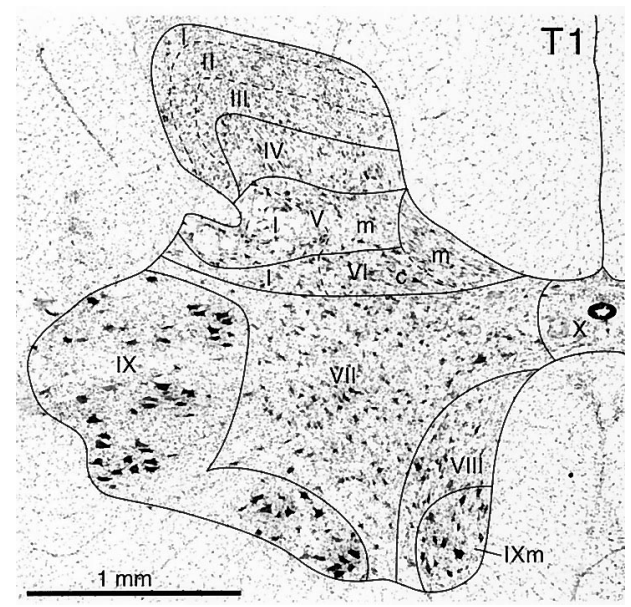

Figure 3. Laminar organization of the cervical spinal cord. Photomicrograph of a coronal section of spinal segment $\mathrm{T} 1$ of a macaque stained with cresyl violet. Laminar borders adapted from the criteria of Rexed (1952) and Apkarian and Hodge (1989). $c$, Central; $l$, lateral; $m$, medial.
The overall distribution of reaction product was assessed by gradient density analysis of illuminated pixels, defined as those pixels in the gray matter with intensity values above background levels (Bortoff and Strick, 1993). The intensity levels of these pixels were color-coded: white $=$ the most intense $10 \%$ of the pixels $(90-100 \%)$, yellow $=60-90 \%$ levels, red $=30-60 \%$ levels, and blue $=$ least intense $30 \%$ of pixels. The percentage of labeling in each lamina of a segment was determined by dividing the number of illuminated pixels in that lamina by the total number of illuminated pixels in the gray matter of that segment and then multiplying by 100 . This measurement provides an indication of the distribution of reaction product in the gray matter. The percentage of a lamina containing labeling was determined by dividing the number of illuminated pixels in a lamina by the total number of pixels in the lamina and then multiplying by 100 . This measurement was used to compare the density of labeling among the different laminae and among different animals. Intensity of the illuminated pixels was not included in either of these calculations.

\section{RESULTS}

\section{Location of cortical injection sites}

The injection sites in the SMA and in the CMAd/CMAv involved all of the portions of these areas that project to cervical segments of the spinal cord (Figs. 1, 2) (Dum and Strick, 1991b; He et al., 1995). These injection sites were, by design, large, and extended beyond the borders of the arm representation to include representations of other body parts (Fig. $2 A, B$ ). Because corticospinal projections from the SMA and CMAd/CMAv are somatotopically organized (He et al., 1995), the involvement of face or leg representations in our injection sites should not influence our results.

Both SMA injection sites included the portion of the SMA on the dorsal lip of the cingulate sulcus. This portion of the SMA contains a dense concentration of neurons that project to the lower cervical segments (He et al., 1995). Further involvement of 
Table 1. Experimental protocols

\begin{tabular}{|c|c|c|c|c|c|c|}
\hline Animal & $\begin{array}{l}\text { Weight } \\
(\mathrm{kg})\end{array}$ & $\begin{array}{l}\text { Cortical } \\
\text { area }^{a}\end{array}$ & $\begin{array}{l}\text { No. of } \\
\text { needle } \\
\text { tracks }\end{array}$ & $\begin{array}{l}\text { No. of } \\
\text { injection } \\
\text { sites }\end{array}$ & $\begin{array}{l}\text { Total } \\
\text { volume } \\
\text { injected }(\mu \mathrm{l})\end{array}$ & $\begin{array}{l}\text { WGA-HRP } \\
\text { concentration } \\
\text { (percent) }\end{array}$ \\
\hline $\mathrm{R} 4$ & 13.8 & M1 & 13 & 27 & 1.35 & 2 \\
\hline $\mathrm{R} 5$ & 13.7 & SMA & 35 & 35 & 1.75 & 2 \\
\hline R9 & 8.7 & CMAd/CMAv & 14 & 52 & 2.60 & 10 \\
\hline $\mathrm{R} 10$ & 12.7 & CMAd/CMAv & 15 & 59 & 2.95 & 10 \\
\hline
\end{tabular}

${ }^{a}$ Bold indicates representative animal and its designation throughout this paper.

the dorsal bank was carefully limited to avoid the CMAd (He et al., 1995). The SMA injection sites spread caudally to involve some of the adjacent leg representation in M1. However, this portion of M1 has no terminations in the cervical segments of the spinal cord (He et al., 1993, 1995).

The CMAd/CMAv injection sites in animals R9 and R10 began at the level of the arcuate genu and extended caudally to $4-5 \mathrm{~mm}$ rostral to the central sulcus (Fig. $2 B$ ). The ventral bank of the cingulate sulcus was more completely filled than the dorsal bank in both animals. In addition, because the injection needles passed through the SMA as they entered the dorsal bank of cingulate sulcus, some tracer injections involved a portion of the adjacent SMA. The injection sites and the patterns of terminations of the two CMAd/CMAv animals were similar. Therefore, the results of one CMAd/CMAv animal will be illustrated (R9).

The separate injections into the CMAd and CMAv (Fig. 2C) involved portions of these cortical areas that project to the cervical cord and to the arm area of the primary motor cortex (Dum and Strick, 1991b; Shima et al., 1991; Morecraft and Van Hoesen, 1992; Lu et al., 1994; He et al., 1995). Tracer injections into either area resulted in large numbers of labeled neurons in the arm area of M1. The tracer injection into the CMAv labeled neurons primarily in the portion of M1 that lies on the crest of the precentral gyrus. In contrast, the injection into the CMAd labeled neurons in the portion of M1 that lies in the anterior bank of the central sulcus, as well as on the precentral gyrus (Holsapple and Strick, 1991). No labeling was found in the leg representation of M1 in either case.

The injection site in M1 was confined primarily to area 4 except for a small incursion into area 3 a laterally (Fig. $2 A$ ). It is likely that the injection site included all of the distal forelimb represen- tation of M1 in the anterior bank of the central sulcus (Fig. 2A) (Woolsey et al., 1952; Kwan et al., 1978; Sato and Tanji, 1989; He et al., 1993). We sought to avoid any spread of tracer rostrally into the adjacent arm representations of the PMv and PMd. As a result, some of the proximal arm representation in M1 (Woolsey et al., 1952; Kwan et al., 1978; He et al., 1993) was not included in the injection site.

\section{Patterns of termination in cervical segments}

\section{SMA: contralateral terminations}

Within the cervical enlargement (C5-T1), 77\% of the terminations of SMA efferents were on the contralateral side (Figs. 4-7). Most of these terminations $(87 \%)$ were confined to the intermediate zone (laminae V-VIII) (Kuypers, 1981). Terminations were also present in the ventral horn (lateral and medial motoneuron cell columns in lamina IX) and represented $\sim 11 \%$ of the contralateral terminations. Only minimal labeling (2\%) was found in the dorsal horn (laminae I-IV).

Within the intermediate zone, terminations were most concentrated in three regions (Fig. 4). These were located: (1) laterally within laminae V-VII, adjacent to the dorsolateral funiculus; (2) dorsomedially within lamina VI, at the base of the dorsal horn; and (3) ventromedially within lamina VII and extending somewhat into lamina VIII, adjacent to the ventromedial funiculus (sites correspond to numbered arrows in Fig. 4). This pattern of termination was present at all levels of the cervical cord (Fig. 6).

Terminations were found throughout the lateral cell column of lamina IX at all cervical levels. The terminations at this site were most dense dorsolaterally, particularly in lower cervical segments (C7-T1) where the motoneurons that innervate distal limb musculature are located (Fig. 4, numbered arrow 4) (see also Figs. 6, 8)
Figure 4. Corticospinal terminations in contralateral C7. A, Photomicrograph under dark-field/polarized light of TMB labeling after WGA-HRP injections into the SMA. SMA efferents terminate densely in four regions of the gray matter (numbered arrows; see Results for further description). $B$, TMB labeling after injections into M1. M1 efferents terminate densely in the same four regions of the gray matter, as do SMA efferents. Laminar borders are indicated as in Figure 3.
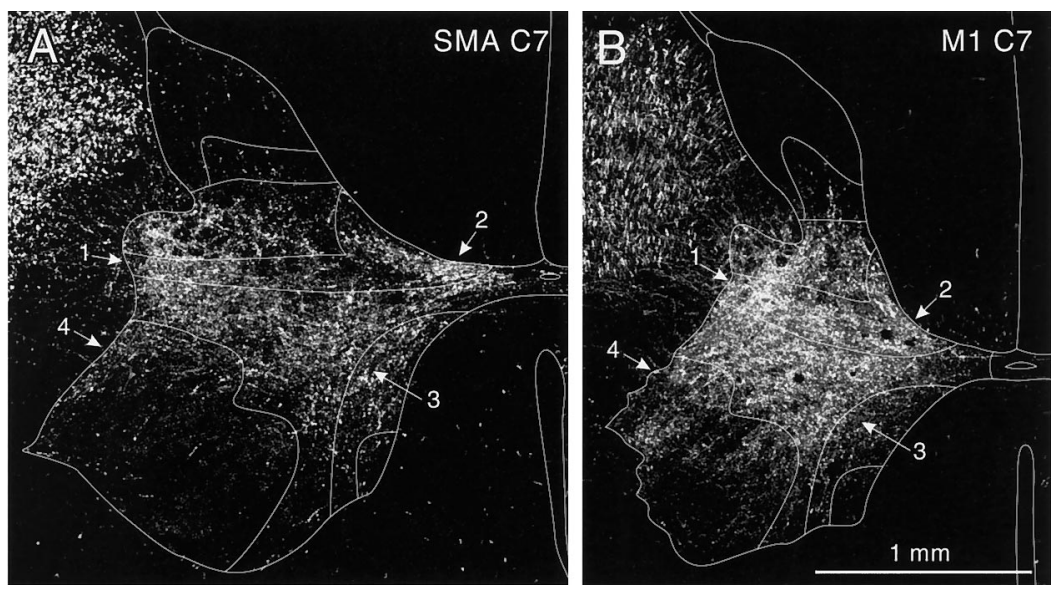

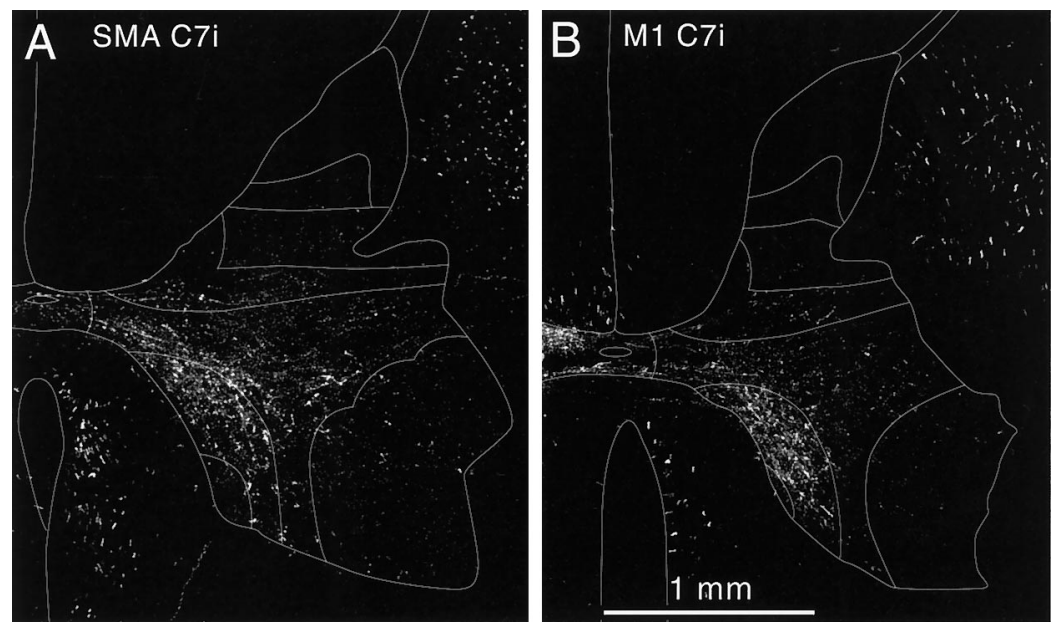

Figure 5. Corticospinal terminations in ipsilateral C7. $A$, TMB labeling after WGA-HRP injections into the SMA. $B$, TMB labeling after injections into M1. Laminar borders are indicated as in Figure 3.

(Jenny and Inukai, 1983). Sparse labeling also was present throughout the medial cell column of lamina IX where motoneurons innervating axial musculature are located (Reed, 1940; Sprague, 1948).

\section{SMA: ipsilateral terminations}

On average, 23 percent of the SMA terminations in the cervical enlargement were on the ipsilateral side (Figs. 5, 7). The proportion of ipsilateral terminations was somewhat greater in upper cervical segments (C2-C4, 29\%). Most of the ipsilateral terminations (84\%) were located in lamina VIII and the medial half of lamina VII. Surprisingly, the density of the terminations in lamina VIII on the ipsilateral side was comparable to that on the contralateral side (Figs. $4,5,7)$. Although the remainder of the ipsilateral terminations were of moderate-to-sparse density, these terminations were found at all of the sites in the intermediate zone and ventral horn that received contralateral terminations (Fig. 5).

\section{CMAd/CMAv: contralateral terminations}

The overall density of CMAd/CMAv terminations was clearly less than that from the SMA (Figs. 7, 9). On the other hand, the topographic distributions of terminations from the CMAd/CMAv and SMA were quite similar (Figs. 6, 9). Ninety-one percent of the terminations of CMAd/CMAv efferents were on the contralateral side in the cervical enlargement (Fig. 7). Most (90\%) of these terminations were confined to the intermediate zone of the spinal cord. However, sparse terminations (4\%) were consistently present in the ventral horn, particularly in the lateral cell column. Interestingly, sparse terminations also were present in the dorsal horn. The density of these terminations was low in lower cervical segments (6\%), but increased in upper cervical segments (14\%), particularly in laminae III and IV (Figs. 7, 9).

Within the intermediate zone, efferents from the CMAd/CMAv terminated densely within largely the same three regions that receive dense input from the SMA: (1) the lateral portion of laminae V-VI; (2) the dorsomedial portion of lamina VI; and (3) the ventromedial portion of lamina VII (Fig. 9). CMAd/CMAv terminations were less extensive in lamina VIII than those from the SMA. The three sites of termination in the intermediate zone were present at all levels of the cervical cord.

The CMAd/CMAv terminations in the lateral cell column of lamina IX, like those from the SMA, were concentrated dorsolaterally. However, the terminations at this site in C5 were denser than those at C7-T1. This pattern was seen in both of the CMAd/CMAv animals.

\section{CMAd/CMAv: ipsilateral terminations}

On average, ipsilateral CMA terminations comprised only 9 percent of the terminations in the cervical enlargement (Fig. 7), although the proportion of ipsilateral terminations was somewhat greater in the upper cervical segments $(14 \%)$. Most (78\%) of the terminations in the cervical enlargement were divided between the medial half of lamina VII and lamina VIII. Compared with the SMA, the CMAd/CMAv contributes relatively less input to the ipsilateral cervical cord.

\section{Terminations from individual cingulate motor areas}

It is important to remember that our large tracer injections into the banks of the cingulate sulcus examined the descending projections from two cortical areas: the CMAd and CMAv. These injections were intentionally made large to label the efferents from these areas as completely as possible. In other animals, we made smaller injections into either bank of the cingulate sulcus to examine separately the efferents from each cortical area.

Small tracer injections into either the CMAd or the CMAv resulted in terminations in the intermediate zone and in the ventral horn (Fig. 10). Terminations after the CMAd injection were most concentrated in the dorsolateral part of the intermediate zone (lateral laminae V-VI) (Fig. 10A). In contrast, terminations after the CMAv injection were most concentrated in the dorsomedial part of the intermediate zone at the base of the dorsal columns (lamina VI) (Fig. 10B). These observations indicate that the pattern of terminations seen after the large CMAd/ CMAv injections actually represents the sum of two distinct efferent systems.

The sparse labeling in the ventral horn after tracer injections into either the CMAd or the CMAv was located dorsolaterally in the lateral cell column. The presence of this labeling, even after small tracer injections, indicates that much of the labeling in the lateral cell column after the CMAd/CMAv injections is truly attributable to efferents from these areas and not to spread of tracer to adjacent regions of the SMA. Thus, the CMAd and CMAv both have some input to the lateral motoneuronal cell column in lamina IX (Figs. 7-9). 

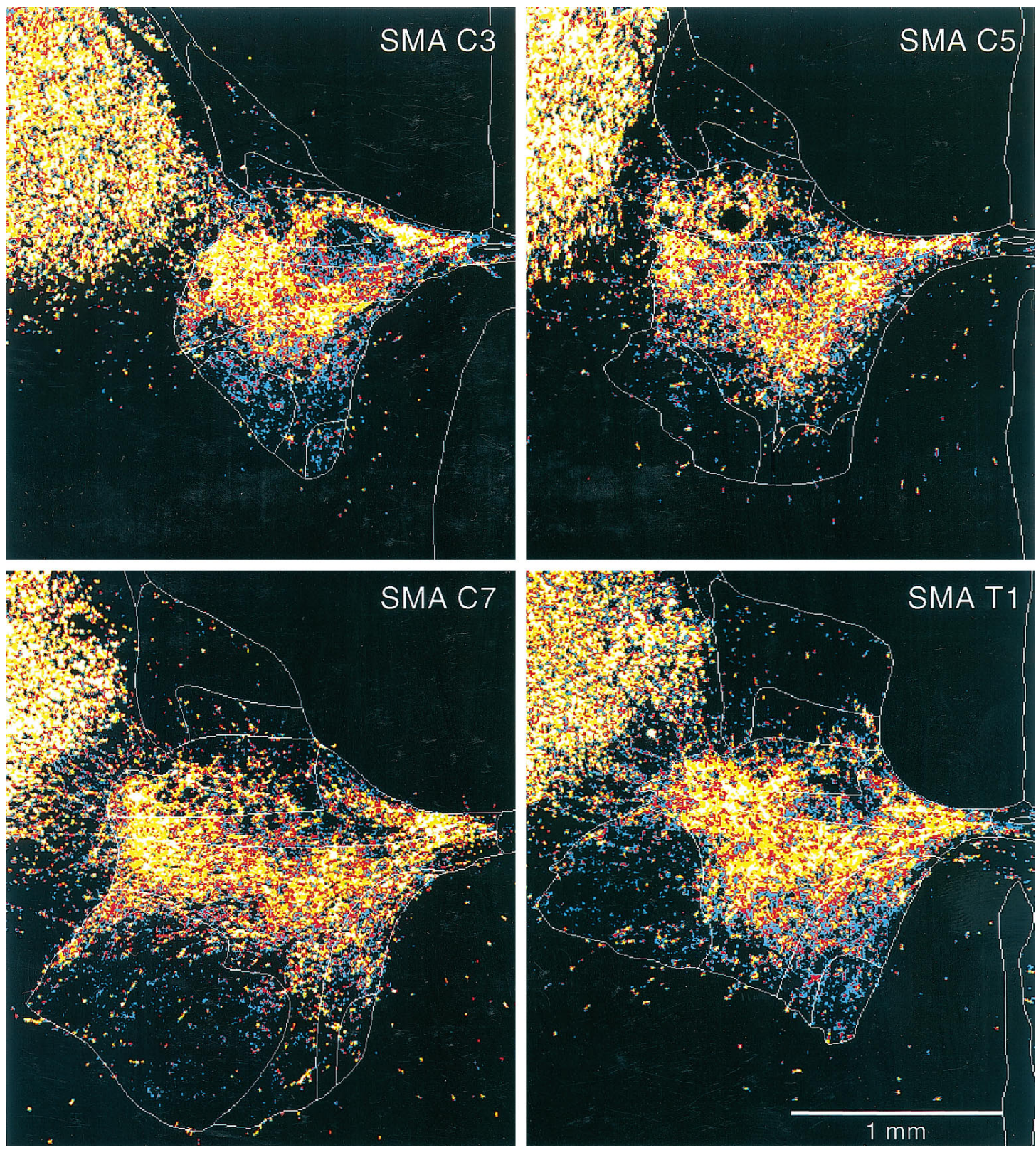

Figure 6. SMA terminations in contralateral cervical segments of animal R3. Each figure shows a gradient density analysis of corticospinal terminations at one of four segmental levels in the cervical spinal cord. Digitally captured images of spinal cord terminations were color-coded: white $=$ the most intense $10 \%$ of illuminated pixels, yellow $=60-90 \%$, red $=30-60 \%$, blue $=$ the least intense $30 \%$. The pattern of SMA terminations at each segmental level is similar and includes some terminations in dorsolateral lamina IX where motoneurons are located.

\section{M1: contralateral terminations}

Within the cervical enlargement, $>82 \%$ of the terminations of efferents from the M1 were on the contralateral side (Figs. 4, 5, 7, 11). Most $(70 \%)$ of these terminations were confined to the intermediate zone of the spinal cord (laminae V-VIII) (Kuypers, 1981). Substantial terminations were present throughout the cervical segments in lamina IX, particularly in the cervical enlargement where they constituted 28 percent of the contralateral labeling (Figs. 7, 8). Only minimal labeling $(<2 \%)$ was ever found in the dorsal horn of the cervical segments.

The bulk of M1 labeling in the spinal cord was located in the same four regions of the cervical gray matter that were labeled from the SMA. However, the extent and density of M1 labeling was greater (Figs. 4, 7, 11). Most notable, the labeling from M1 to lamina IX was significantly enhanced throughout the cervical enlargement (Fig. 8). The increased density and extent of labeling in lamina IX of the M1 animal was maximal in T1 where reaction product covered large portions of lateral lamina IX (Fig. 11). Despite this increase, the M1 terminations, like those from the SMA, tended to be concentrated in the dorsolateral part of lamina IX and in the part of lamina IX that lies adjacent to lamina VII. This similarity with the SMA terminations was evident throughout the cervical enlargement.

M1 injections produced sparse labeling in the medial group of motor nuclei (Figs. 7, 11). Although the density of these projections was somewhat less than those observed in the same region after injections into the SMA, the two injection sites were not equivalent. The M1 injection site was limited to its arm represen- 

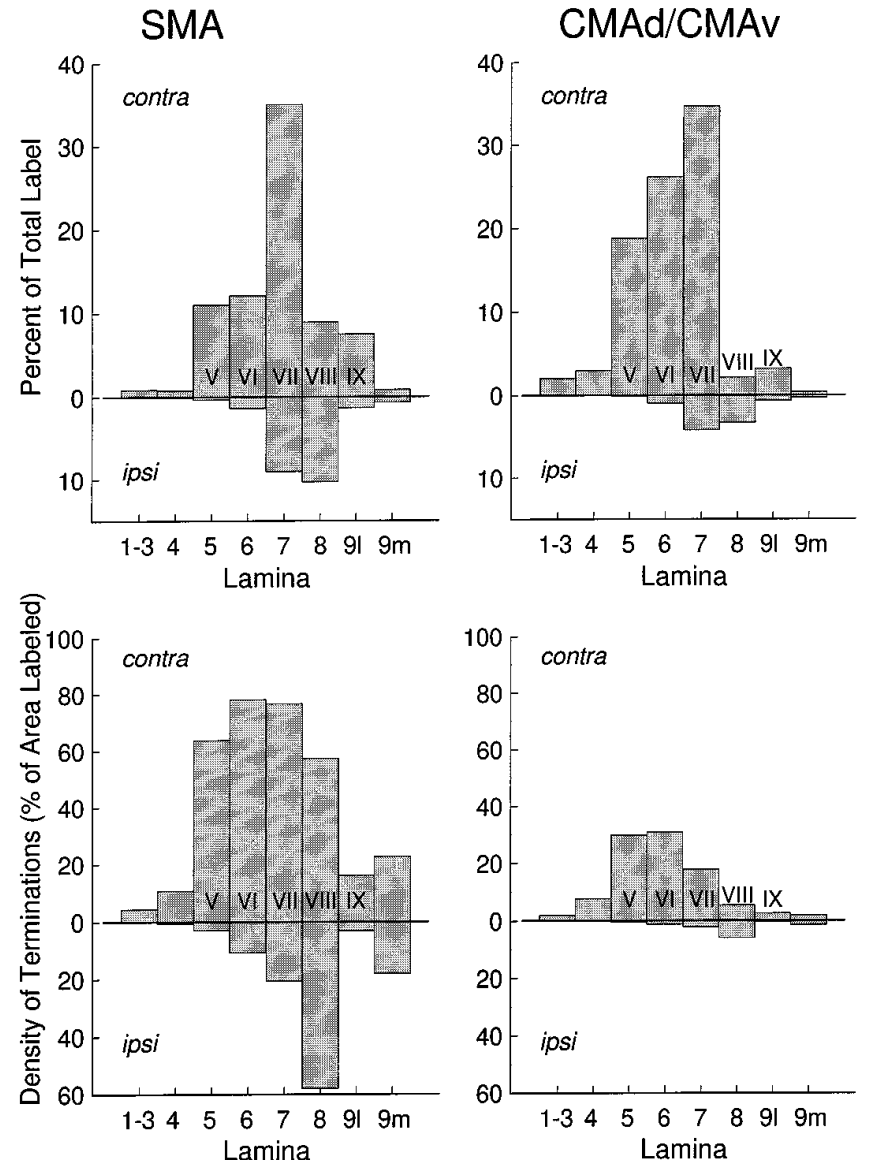

tation, whereas the SMA injection included its arm, as well as parts of its trunk and leg representations.

The pattern of M1 terminations in the cervical cord was remarkably similar to that of the SMA. In fact, in the upper cervical segments, the distribution of terminations from M1 within different lamina of the spinal cord did not differ significantly from that of the SMA (chi-square $=8.53$; $\mathrm{df}=7 ; 0.25<p<0.5$ ). There was a significant difference between M1 and SMA terminations in lower cervical segments (chi-square $=34.38$; $\mathrm{df}=7 ; p<0.0001$ ). However, this difference was entirely attributable to the large increase in the proportion of terminations found in lamina IX after M1 injections.

\section{M1: ipsilateral terminations}

On average, ipsilateral M1 terminations comprised $\sim 18 \%$ of the terminations in the cervical enlargement. Most of these terminations $(76 \%)$ were divided between lamina VIII and the medial half of lamina VII. However, sparse ipsilateral terminations were found at all of the sites that receive contralateral terminations, including the ventral horn. As with the SMA, the density and distribution of terminations from M1 in ipsilateral lamina VIII were comparable to those in contralateral lamina VIII.

\section{DISCUSSION}

Our study is the first to illustrate the spinal cord terminations of efferents from the SMA, CMAd, and CMAv. We found that the majority of the corticospinal efferents from these motor areas, as well as those from M1, terminates in the intermediate zone of the spinal cord. This suggests that all of these cortical areas influence spinal mechanisms of movement control primarily through con-

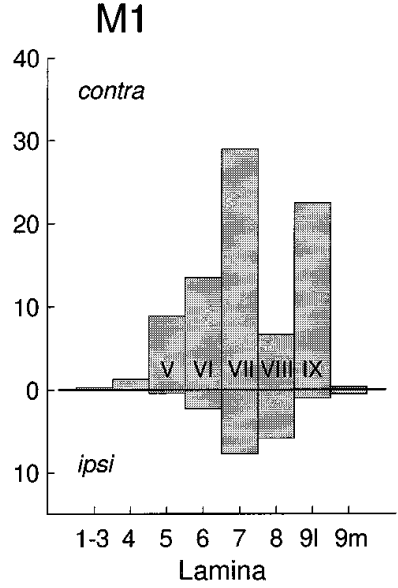

Figure 7. Quantitative analysis of corticospinal terminations. Top row, Histograms indicate the percentage of the total number of illuminated pixels that were found in each lamina. The percentage of total label in a lamina was calculated separately for each segment of the cervical enlargement (C5-T1) and then was averaged across segments to determine the values represented in a histogram. The histograms provide an indication of the overall distribution of terminations to each lamina from the SMA (animal R3), CMAd/CMAv (animals R9 and R10), and M1 (animal R4). Bottom row, Histograms indicate the percentage of area in each lamina that had illuminated pixels. These values are averages for all segments of the cervical enlargement. $9 l$, Lateral cell column of lamina IX; $9 m$, medial cell column of lamina IX.

nections with a common set of interneurons. Our second major observation is that each of the cortical areas examined has some terminations within lamina IX where motoneurons are located. This observation suggests that efferents from the SMA, CMAd, and CMAv, like those from M1, make monosynaptic connections with motoneurons. These two results indicate that the anatomical substrate exists for the motor areas on the medial wall of the hemisphere to directly control arm movements independent of output from M1. Thus, the observations of the present study further support our proposal that corticospinal efferents from the SMA, CMAd, CMAv, and M1 represent parallel channels for motor output (Dum and Strick, 1991a,b; He et al., 1993, 1995).

Our statements about "terminations" are based on a number of assumptions. For the present experiment, the three most important are: (1) TMB reaction product in spinal cord gray matter largely reflects labeling of the terminal boutons and the preterminal arbors of corticospinal efferents (Cheema et al., 1984; Ralston and Ralston, 1985; LaMotte et al., 1991); (2) the density of reaction product at a given site in the gray matter is monotonically related to the density of terminations at that site (Mesulam, 1982; LaMotte et al., 1991); and (3) the majority of the terminations in a given lamina innervate neurons in that lamina (Cheema et al., 1984; Ralston and Ralston, 1985). Given these assumptions, the conclusions that we draw about the site of termination of corticospinal efferents should be verified in future studies using physiological methods and electron microscopic techniques.

In general, we observed that tracer injections into M1 demonstrated corticospinal terminations in the same regions of the spinal cord as reported previously (Kuypers, 1960; Liu and Cham- 

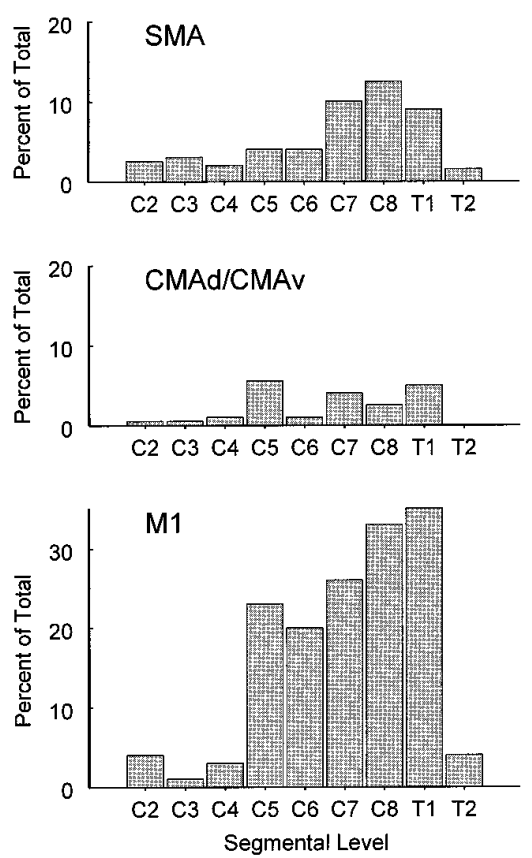

Figure 8. Percentage of the illuminated pixels in the contralateral gray matter that are located in the lateral cell column of lamina IX. The $C M A d / C M A v$ and $S M A$ histograms each represent the average of two animals.

bers, 1964; Kuypers and Brinkman, 1970; Cheema et al., 1984; Ralston and Ralston, 1985; Bortoff and Strick, 1993). However, some minor differences in the relative distribution are evident, particularly when our results are compared with those of studies that used degeneration techniques (Liu and Chambers, 1964; Kuypers and Brinkman, 1970). For example, we observed relatively more terminations from M1 medially in lamina VI than was illustrated in previous studies (Kuypers, 1960; Liu and Chambers, 1964; Kuypers and Brinkman, 1970). This difference may indicate that WGA-HRP labels the terminations of some (perhaps small) corticospinal axons more efficiently than degeneration techniques (Cheema et al., 1984; LaMotte et al., 1991).

\section{Input to motoneurons}

Each of the cortical areas examined has some terminations within motor nuclei of the ventral horn. In the past, physiological studies have found that the presence of such terminations is indicative of monosynaptic connections with motoneurons, even when the terminations were sparse (Phillips and Porter, 1977; Kuypers, 1981; Bortoff and Strick, 1993; Lemon et al., 1996). Thus, our observations imply that some corticospinal efferents from the SMA, CMAd, and CMAv have monosynaptic connections with motoneurons.

The terminations from each of the cortical areas examined were scattered throughout the ventral horn. However, they were clearly densest in dorsolateral portions of lamina IX where motoneurons innervating distal forelimb muscles are located (Jenny and Inukai, 1983). This preferential distribution of terminations within lamina IX suggests that corticomotoneuronal connections from all the areas examined are focused on motoneurons innervating muscles of the fingers and wrist. This conclusion is consistent with our observation that the size of the distal arm representation in the CMAd and CMAv is larger than that of the proximal arm (He et al., 1995). Furthermore, the incidence of short latency effects evoked by poststimulus facilitation of the SMA was higher for hand muscles $(55 \%)$ than for proximal arm muscles $(30 \%)$ (Hummelsheim et al., 1986). Thus, the present observations further emphasize the potential involvement of the medial wall motor areas in the generation and control of distal limb movement (for discussion, see He et al., 1995).

Although each of the cortical areas we examined terminates within the ventral horn, the density and extent of this projection varied. M1 had the densest terminations, and the least dense were from CMAd and CMAv. SMA terminations were intermediate. In part, this gradient of input to the ventral horn parallels the relative size of these cortical areas, and the number and size of corticospinal neurons in each area (Dum and Strick, 1991b; He et al., 1995). It is possible that these variations in density also reflect the extent to which each of these areas is directly concerned with determining the specific parameters of motor output. For example, M1 projections to the ventral horn are thought to be critically important for determining the patterns of muscle activity necessary to generate relatively independent movements of the fingers (Kuypers, 1981; Bortoff and Strick, 1993) and specific directions of wrist movement (Hoffman and Strick, 1995). The medial wall motor areas may be relatively more concerned with delivering descending commands to motoneurons related to more abstract features of motor output, such as motor preparation and the central set to move (Shima et al., 1991; Tanji, 1994).

On the other hand, all of the motor areas contain neurons that change their activity before the onset of relatively simple motor tasks, such as a key press or flexion-extension movements of the elbow (Crutcher and Alexander, 1990; Shima et al., 1991; Tanji, 1994). Furthermore, the SMA (Smith, 1979) and CMAv (Cadoret and Smith, 1995) contain neurons that are active before and during precision grip, and modulate their activity in a momentby-moment relation to changes in grip force. These physiological observations and our demonstration of corticospinal projections to the ventral horn suggest that each of the motor areas on the medial wall is not solely concerned with higher-order aspects of motor behavior, but also can contribute to the generation of the specifics of motor output.

\section{Input to the intermediate zone}

One of the striking observations of the present study is the differential projections of the CMAd and CMAv on the intermediate zone. Projections from the CMAd were most concentrated in the dorsolateral portion of the intermediate zone, whereas those from the CMAv were most concentrated in dorsomedial portions. Our interpretation of the significance of these results is limited by the relative dearth of information available on the functional contributions of different regions within the intermediate zone. They are also hampered by the lack of information on the segmental organization of the cervical cord in the monkey, because most studies on this issue have been performed in the cat.

However, based on the information available, the two regions of the intermediate zone that receive input from the CMAd and CMAv have some features in common. Physiological studies confirm that some interneurons at both sites receive input from the pyramidal tract and directly excite or inhibit motoneurons (Jankowska et al., 1976; Hongo et al., 1989). Both regions contain neurons that are considered "last-order interneurons" in reflex circuits because they make direct connections to motoneurons. Many of the connections of interneurons in the dorsolateral and dorsomedial portions of the intermediate zone are with motoneurons that innervate distal forelimb muscles (Grant et al., 1980; 

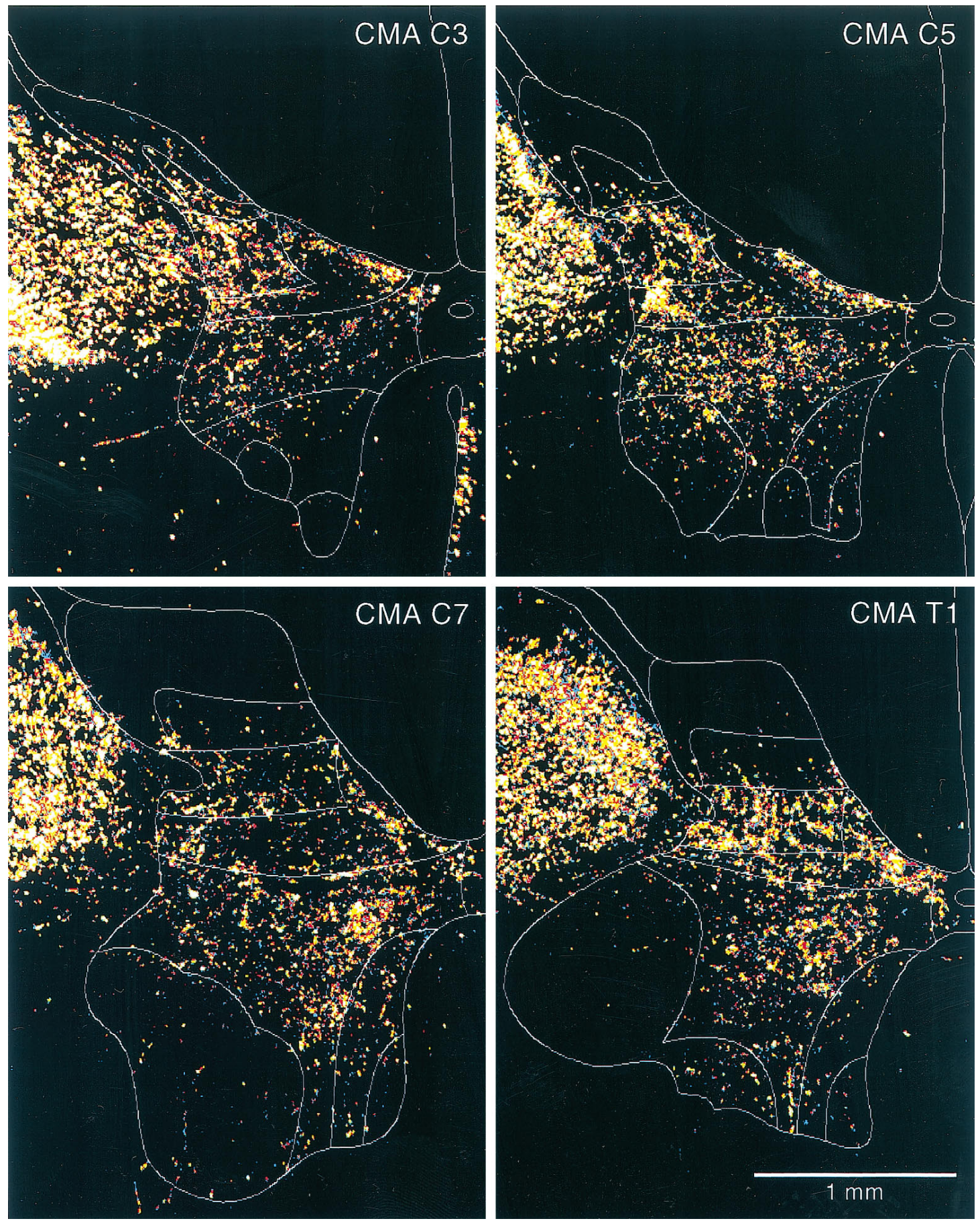

Figure 9. CMAd/CMAv terminations in contralateral cervical segments of animal R9. These images are displayed using the same conventions as in Figure 6. The pattern of CMAd/CMAv terminations at each cervical level is similar to the SMA pattern (Fig. 6), except in medial lamina VIII.

Hongo et al., 1989). Thus, it is possible that the CMAd and CMAv terminations at these sites innervate some interneurons that are involved in the control of distal limb movements.

On the other hand, several unique types of interneurons have been found within each region of the intermediate zone. For instance, Ia inhibitory interneurons are preferentially located in the dorsolateral part of the intermediate zone in lateral lamina VII in both cats and monkeys (Hultborn et al., 1976; Jankowska et al., 1976). These physiological studies demonstrated that Ia inhibitory interneurons receive monosynaptic input from the pyramidal tract. Because the direct effects of corticospinal synapses are by and large excitatory (Porter and Lemon, 1993), an interaction between these descending systems and the Ia inhibitory neuron may be critically important for shaping motor output (i.e., turning off some muscles while turning on others).

In cats, another set of interneurons is located near the dorsomedial region of the intermediate zone. These interneurons receive input from several descending systems, including the pyramidal tract, and are part of a short-latency cutaneous reflex pathway to distal forelimb motoneurons (Hongo et al., 1989). If 

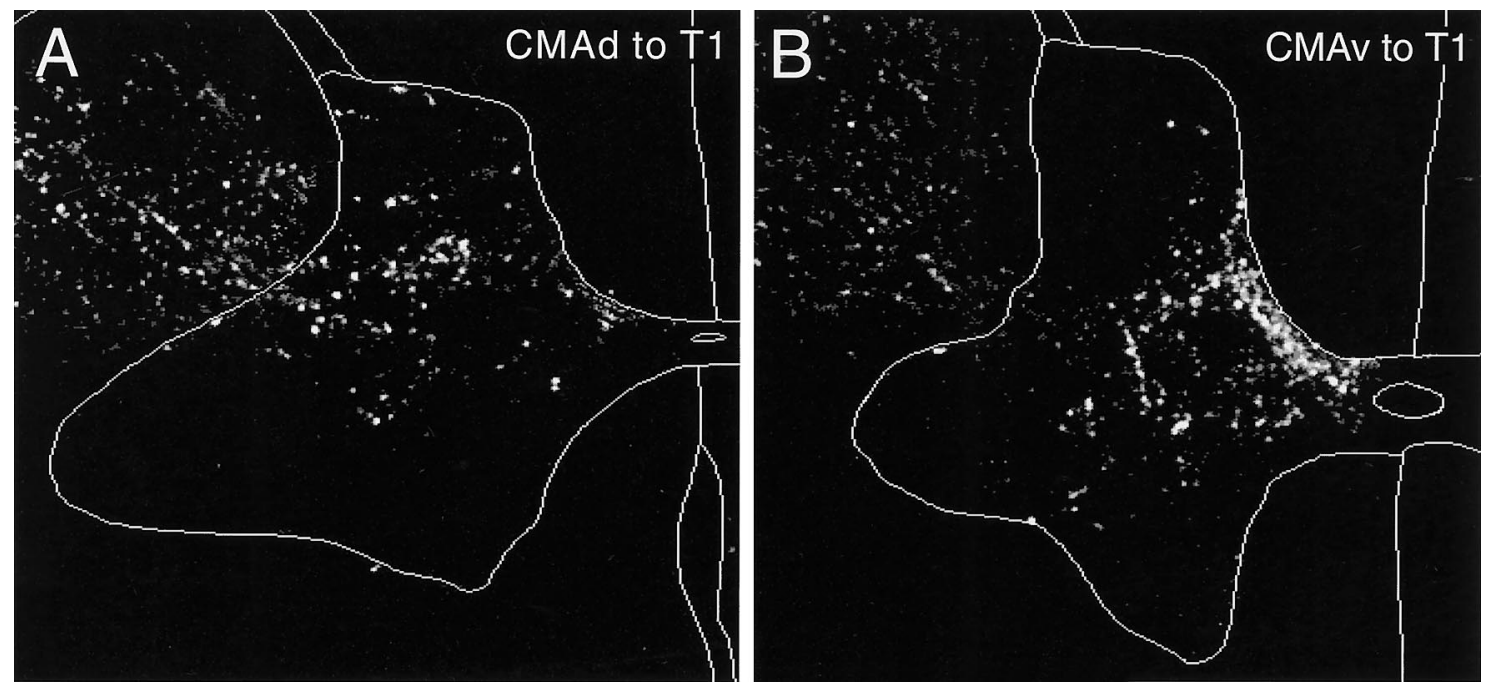

Figure 10. CMAd and CMAv terminations in contralateral T1. $A$, TMB labeling after injections into the CMAd (animal J6). B, TMB labeling after injections into the CMAv (animal J7). These images are displayed using the same conventions as in Figure 6 except they are presented in gray scale.

this type of interneuron also exists in monkeys, then one interpretation of the distinct patterns of projection of the CMAd and CMAv is that each motor area innervates separate sets of lastorder interneurons. As a result, each motor area could influence unique aspects of the segmental control of motor output.

Still another possible target of terminations in the intermediate zone are neurons that are the origin of ascending pathways. For example, spinothalamic neurons are located in dorsolateral portions of the intermediate zone (Hayes and Rustioni, 1980; Apkarian and Hodge, 1989) where efferents from the CMAd terminate. Physiological recordings in monkeys have demonstrated that some spinothalamic tract neurons in this lamina receive monosynaptic excitation from M1 (Yezierski et al., 1983; Zhang et al., 1991). In contrast, spinal neurons that project to the dorsal column nuclei are located in dorsomedial portions of the intermediate zone (Molenaar and Kuypers, 1978; Hayes and Rustioni, 1980) where efferents from the CMAv terminate. Thus, the distinct patterns of termination of the CMAd and CMAv within the intermediate zone may reflect a differential innervation of neurons contributing to various ascending pathways. Clearly, firmer conclusions about the CMAd and CMAv influence on the intermediate zone must await experiments that determine which sets of neurons actually receive input from each cortical area.

Efferents from the SMA and M1 terminate more broadly in the intermediate zone than do those from the CMAd and CMAv. SMA and M1 terminations are dense in both dorsolateral and dorsomedial portions of the intermediate zone. These observations imply that the SMA and M1 gain access to multiple neuron types in the intermediate zone. Thus, the SMA and M1 appear to differ from the cingulate motor areas in having the potential to exert a broader influence over the generation and control of movement.

The SMA and M1 also have dense, bilaterally symmetrical corticospinal projections to the ventromedial portion of the intermediate zone (lamina VIII and adjacent lamina VII) (Fig. 7). Conversely, the CMAd and CMAv have only sparse terminations in this region, even after extensive injections of tracer. The ventromedial portion of the intermediate zone is thought to be involved in the control of axial and proximal body musculature (Reed, 1940; Sprague, 1948; Sterling and Kuypers,
1968; Kuypers and Brinkman, 1970) (for review, see Kuypers, 1981). Thus, both the SMA and M1 appear to have a stronger influence over the control of axial/proximal body musculature than the CMAd and CMAv, at least at the segmental level (Figs. 4, 5, 7).

Some authors have proposed that the SMA is relatively more concerned with the control of axial/proximal muscles than is M1 (Wiesendanger et al., 1973; Luppino et al., 1991, 1993) (but see Tanji, 1994). The higher proportion of SMA terminations in the ventromedial part of the intermediate zone could be construed as support for this proposal. However, our tracer injections filled almost the entire body map of the SMA, whereas the injection site in M1 spared the leg representation and involved little of the axial body and proximal forelimb representation. The hindlimb representations in M1 and the SMA have no terminations in cervical segments. However, corticospinal efferents from the forelimb representations of these cortical areas are quite topographically organized (He et al., 1993, 1995). Thus, the difference between M1 and the SMA in the relative amount of ventromedial terminations may simply reflect dissimilar involvement of their arm areas in the injection sites.

It is noteworthy that all of the motor areas examined project bilaterally not only to the ventromedial part of the intermediate zone, but also to other regions of the intermediate zone and ventral horn. In fact, $>10 \%$ of the total terminations from the SMA and M1 are located in ipsilateral laminae VI, VII, and IX. Thus, the anatomical substrate exists for the motor areas in one hemisphere to influence the control of proximal and distal movements on both sides of the body (Chollet et al., 1991; Kim et al., 1993).

\section{Implications for medial wall involvement in recovery of motor function}

A substantial recovery of motor function can follow removal of the motor cortex in primates (Passingham et al., 1983; Hoffman and Strick, 1995). Several lines of evidence have suggested that the motor areas on the medial wall of the hemisphere might contribute to this process. Normally, many neurons in the SMA are active before the onset of simple movements (Brinkman and Porter, 1979; Smith, 1979; Tanji and Kurata, 1979; Crutcher and Alexander, 1990). However, Aizawa et al. (1991) 

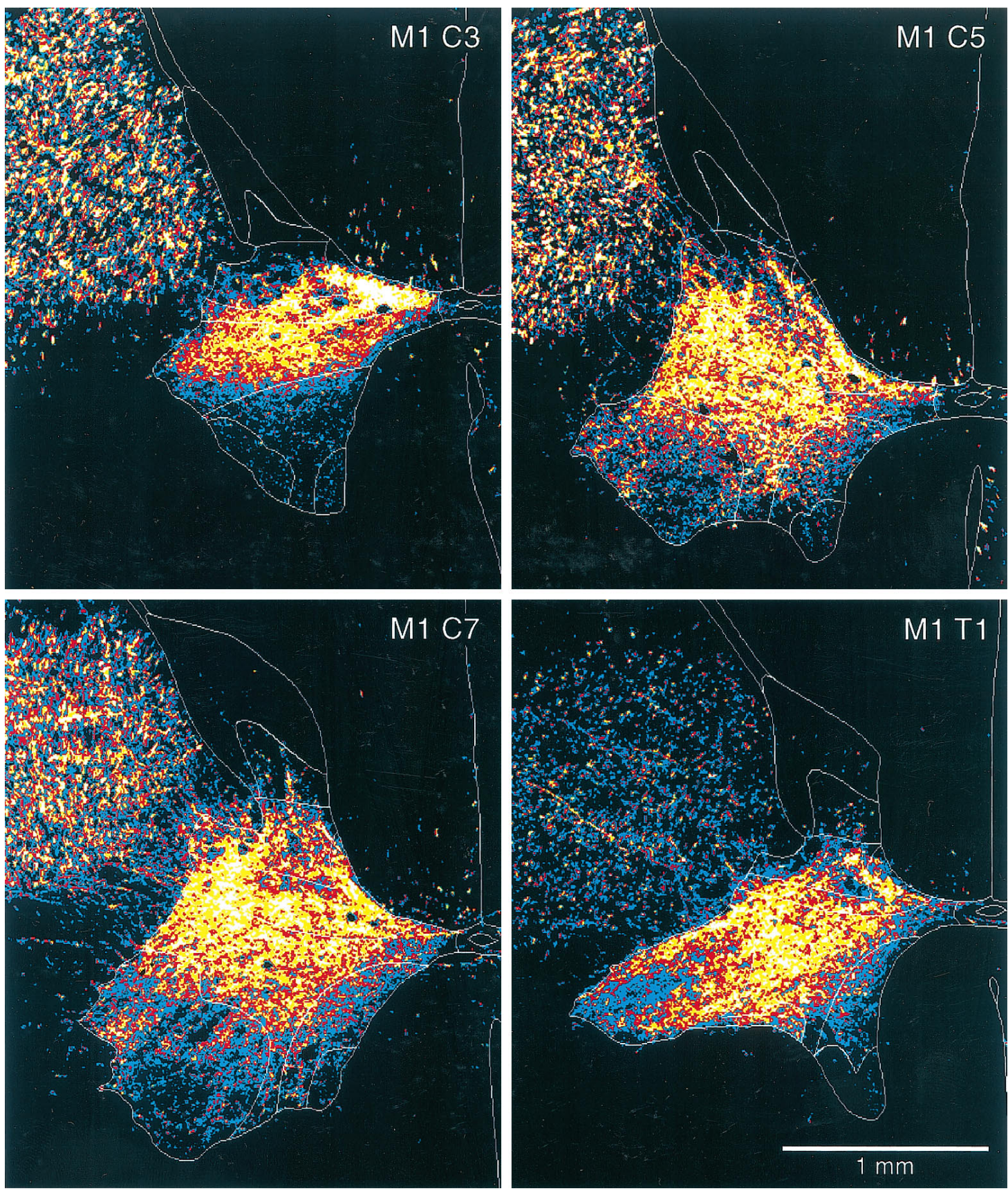

Figure 11. M1 terminations in contralateral cervical segments of animal R4. These images are displayed using the same conventions as in Figure 6. The pattern of M1 terminations at each cervical level is similar to the SMA pattern (Fig. 6), even though the overall density of M1 terminations is higher.

overtrained ( $>1$ year) a monkey to perform a simple key press and found that few SMA neurons were active in relation to the task, let alone discharged before the onset of movement. In contrast, many neurons in M1 of this animal discharged before movement onset. Hence, M1 appeared to be responsible for task execution, and activity in the SMA appeared to decline as the performance became automatic. Then, Aizawa et al. (1991) removed the arm area of the motor cortex. Recordings made when the animal could again perform the simple task found many neurons in the SMA that were active before movement. Thus, SMA activity may have been responsible for the generation of the "recovered" movements.

Similarly, functional activation of motor areas on the medial wall has been examined in human subjects who have demonstrated some recovery of motor function after capsular strokes (Weiller et al., 1993). More pronounced activation was present in the SMA and cingulate motor areas of the damaged hemisphere in these subjects than was present in the same motor areas of control subjects. These observations suggest that medial wall motor areas may be critical to the restitution of motor function after strokes. The results presented above indicate that, under normal circumstances, the SMA, CMAd, and CMAv may contribute to the generation of movements along with M1. There is every reason to believe that alterations in this substrate during the recovery process could enable the medial wall motor areas to initiate movements in the absence of M1. 


\section{REFERENCES}

Aizawa H, Inase M, Mushiake H, Shima K, Tanji J (1991) Reorganization of activity in the supplementary motor area associated with motor learning and functional recovery. Exp Brain Res 84:668-671.

Apkarian AV, Hodge CJ (1989) Primate spinothalamic pathways. I. A quantitative study of the cells of origin of the spinothalamic pathway. J Comp Neurol 288:447-473.

Biber MP, Kneisley LW, LaVail JH (1978) Cortical neurons projecting to the cervical and lumbar enlargements of the spinal cord in young and adult rhesus monkeys. Exp Neurol 59:492-508.

Bortoff GA, Strick PL (1993) Corticospinal terminations in two newworld primates: further evidence that corticomotoneuronal connections provide part of the neural substrate for manual dexterity. J Neurosci 13:5105-5118.

Brinkman C (1982) Supplementary motor area (SMA) and premotor area $(\mathrm{PM})$ of the monkey's brain: distribution of degeneration in the spinal cord after unilateral lesions. Neurosci Lett 8:36.

Brinkman C, Porter R (1979) Supplementary motor area in the monkey: activity of neurons during performance of a learned motor task. J Neurophysiol 42:681-709.

Cadoret G, Smith AM (1995) Input-output properties of hand-related cells in the ventral cingulate cortex in the monkey. J Neurophysiol 73:2584-2590.

Catsman-Berrevoets CE, Kuypers HGJM (1976) Cells of origin of cortical projections to dorsal column nuclei, spinal cord and bulbar medial reticular formation in the rhesus monkey. Neurosci Lett 3:245-252.

Cheema SS, Whitsel BL, Rustioni A (1983) Corticospinal projections from pericentral and supplementary cortices in macaques as revealed by anterograde transport of horseradish peroxidase. Neurosci Lett 14:62.

Cheema SS, Rustioni A, Whitsel BL (1984) Light and electron microscopic evidence for a direct corticospinal projection to superficial laminae of the dorsal horn in cats and monkeys. J Comp Neurol 225:276-290.

Chollet F, DiPiero V, Wise RJS, Brooks DJ, Dolan RJ, Frackowiak RSJ (1991) The functional anatomy of motor recovery after stroke in humans: a study with positron emission tomography. Ann Neurol 29:63-71.

Coulter JD, Jones EG (1977) Differential distribution of corticospinal projections from individual cytoarchitectonic fields in the monkey. Brain Res 129:335-340.

Crutcher MD, Alexander GE (1990) Movement-related neuronal activity selectively coding either direction or muscle pattern in three motor areas of the monkey. J Neurophysiol 64:151-163.

DeVito JL, Smith OA (1959) Projections from the mesial frontal cortex (supplementary motor area) to the cerebral hemisphere and brainstem of the Macaca mulatta. J Comp Neurol 111:261-278.

Dum RP, Strick PL (1991a) Premotor areas: nodal points for parallel efferent systems involved in the central control of movement. In: Motor control: concepts and issues (Humphrey DR, Freund H-J, eds), pp 383-397. London: Wiley.

Dum RP, Strick PL (1991b) The origin of corticospinal projections from the premotor areas in the frontal lobe. J Neurosci 11:667-689.

Dum RP, Strick PL (1993) Supplementary motor area (SMA) input to the cervical cord. Soc Neurosci Abstr 19:1210.

Dum RP, Strick PL (1995) Spinal cord projections from the caudal cingulate motor areas. Soc Neurosci Abstr 21:411.

Dum RP, Strick PL (1996) Spinal cord terminations of the medial wall motor areas. Soc Neurosci Abstr, in press.

Galea MP, Darian-Smith I (1994) Multiple corticospinal neuron populations in the macaque monkey are specified by their unique cortical origins, spinal terminations, and connections. Cereb Cortex 4:166-194.

Gibson AR, Hansma DI, Houk JC, Robinson FR (1984) A sensitive low artifact TMB procedure for the demonstration of WGA-HRP in the CNS. Brain Res 298:235-241.

Grant G, Illert M, Tanaka R (1980) Integration in descending motor pathways controlling the forelimb in the cat. 6. Anatomical evidence consistent with the existence of $\mathrm{C} 3-\mathrm{C} 4$ propriospinal neurones projecting to forelimb motor nuclei. Exp Brain Res 38:87-93.

Hartman CG, Straus WL (1933) The anatomy of the rhesus monkey, pp 1-383. Baltimore: Williams \& Wilkins.

Hayes NL, Rustioni A (1980) Spinothalamic and spinomedullary neurons in macaques: a single and double retrograde tracer study. Neuroscience 5:861-874.
He SQ, Dum RP, Strick PL (1993) Topographic organization of corticospinal projections from the frontal lobe: motor areas on the lateral surface of the hemisphere. J Neurosci 13:952-980.

He SQ, Dum RP, Strick PL (1995) Topographic organization of corticospinal projections from the frontal lobe: motor areas on the medial surface of the hemisphere. J Neurosci 15:3284-3306.

Heffner R, Masterton B (1975) Variation in form of the pyramidal tract and its relationship to digital dexterity. Brain Behav Evol 12:161-200.

Hill WCO (1974) Primates: comparative anatomy and taxonomy, Vol 7, pp 191-583, 661-687. New York: Wiley.

Hoffman DS, Strick PL (1995) Effects of a primary motor cortex lesion on step-tracking movements of the wrist. J Neurophysiol 73:891-895.

Holsapple JW, Strick PL (1991) Pattern of projections from the premotor areas on the medial wall of the hemisphere to the primary motor cortex. Soc Neurosci Abstr 17:1020.

Hongo T, Kitazawa S, Ohki Y, Sasaki M, Xi M (1989) A physiological and morphological study of premotor interneurones in the cutaneous reflex pathways in cats. Brain Res 505:163-166.

Hultborn H, Illert M, Santini M (1976) Convergence on interneurones mediating the reciprocal Ia inhibition of motoneurones. III. Effects from supraspinal pathways. Acta Physiol Scand 96:368-391.

Hummelsheim H, Wiesendanger M, Bianchetti M, Wiesendanger R, Macpherson J (1986) Further investigations of the efferent linkage of the supplementary motor area (SMA) with the spinal cord in the monkey. Exp Brain Res 65:75-82.

Hutchins KD, Martino AM, Strick PL (1988) Corticospinal projections from the medial wall of the hemisphere. Exp Brain Res 71:667-672.

Jankowska E, Padel Y, Tanaka R (1976) Disynaptic inhibition of spinal motoneurones from the motor cortex in the monkey. J Physiol (Lond) 258:467-487.

Jenny AB, Inukai J (1983) Principles of motor organization of the monkey cervical spinal cord. J Neurosci 3:567-575.

Keizer K, Kuypers HGJM (1989) Distribution of corticospinal neurons with collaterals to the lower brain stem reticular formation in monkey (Macaca fascicularis). Exp Brain Res 74:311-318.

Kim SG, Ashe J, Hendrich K, Ellermann JM, Merkle H, Ugurbil K (1993) Functional magnetic resonance imaging of motor cortex: hemispheric asymmetry and handedness. Science 261:615-617.

Kuypers HGJM (1960) Central cortical projections to motor and somato-sensory cell groups. Brain 83:161-184.

Kuypers HGJM (1981) Anatomy of the descending pathways. In: Handbook of physiology, Sec I, The nervous system, Vol II, Motor control, Pt I (Brooks VB, ed), pp 567-666. Bethesda, MD: American Physiological Society.

Kuypers HGJM, Brinkman J (1970) Precentral projections of different parts of the spinal intermediate zone in the rhesus monkey. Brain Res 24:29-48.

Kwan HC, MacKay WA, Murphy JT, Wong YC (1978) Spatial organization of precentral cortex in awake primates. II. Motor outputs. J Neurophysiol 41:1120-1131.

LaMotte CC, Kapadia SE, Shapiro CM (1991) Central projections of the sciatic, saphenous, median, and ulnar nerves of the rat demonstrated by transganglionic transport of choleragenoid-HRP $(\beta$-HRP) and wheat germ agglutinin-HRP (WGA-HRP). J Comp Neurol 311:546-562.

Lawrence DG, Kuypers HGJM (1968) The functional organization of the motor systems in the monkey. I. The effects of bilateral pyramidal lesions. Brain 91:1-14.

Lemon RN, Maier MA, Olivier E, Baker SN, Morris T (1996) Direct cortico-motoneuronal (CM) connections in the squirrel monkey (Samiri sciureus). Soc Neurosci Abstr, in press.

Liu CN, Chambers WW (1964) An experimental study of the corticospinal system in the monkey (Macaca mulatta). J Comp Neurol 123:257-284.

Lu M-T, Preston JB, Strick PL (1994) Interconnections between the prefrontal cortex and the premotor areas in the frontal lobe. J Comp Neurol 341:375-392.

Luppino G, Matelli M, Camarda RM, Gallese V, Rizzolatti G (1991) Multiple representations of body movements in mesial area 6 and adjacent cingulate cortex: an intracortical microstimulation study in the macaque monkey. J Comp Neurol 311:463-482.

Luppino G, Matelli M, Camarda RM, Rizzolatti G (1993) Corticocortical connections of area F3 (SMA-proper) and area F6 (pre-SMA) in the macaque monkey. J Comp Neurol 338:114-140. 
Macpherson JM, Marangoz C, Miles TS, Wiesendanger M (1982) Microstimulation of the supplementary motor area (SMA) in the awake monkey. Exp Brain Res 45:410-416.

Mesulam MM (1982) Tracing neural connections (Mesulam MM, ed), pp 1-151. New York: Wiley.

Molenaar I, Kuypers HGJM (1978) Cells of origin of propriospinal fibers and of fibers ascending to supraspinal levels. A HRP study in cat and rhesus monkey. Brain Res 152:429-450.

Morecraft RJ, Van Hoesen GW (1992) Cingulate input to the primary and supplementary motor cortices in the rhesus monkey: evidence for somatotopy in areas 24c and 23c. J Comp Neurol 322:471-489.

Murray EA, Coulter JD (1981) Organization of corticospinal neurons in the monkey. J Comp Neurol 195:339-365.

Nudo RJ, Masterton RB (1990) Descending pathways to the spinal cord. III. Sites of origin of the corticospinal tract. J Comp Neurol 296:559-583.

Passingham RE, Perry VH, Wilkinson F (1983) The long-term effects of removal of sensorimotor cortex in infant and adult rhesus monkeys. Brain 106:675-705.

Phillips CG, Porter R (1977) Corticospinal neurons: their role in movement, pp 1-450. New York: Academic.

Porter R, Lemon RN (1993) The corticospinal system, pp 1-428. London: Oxford UP.

Ralston DD, Ralston HJ (1985) The terminations of corticospinal tract axons in the macaque monkey. J Comp Neurol 242:325-337.

Reed AF (1940) The nuclear masses in the cervical spinal cord of $M a$ caca mulatta. J Comp Neurol 72:187-207.

Rexed B (1952) A cytoarchitectonic organization of the spinal cord in the cat. J Comp Neurol 96:415-495.

Rosene DL, Mesulam MM (1978) Fixation variables in horseradish peroxidase neurohistochemistry. I. The effects of fixation time and perfusion procedures upon enzyme activity. J Histochem Cytochem 26:28-39.

Rosene DL, Roy NJ, Davis BJ (1986) A cryoprotection method that facilitates cutting frozen sections of whole monkey brains for histological and histochemical processing without freezing artifact. J Histochem Cytochem 34:1301-1315.

Sato KC, Tanji J (1989) Digit-muscle responses evoked from multiple intracortical foci in monkey precentral motor cortex. J Neurophysiol 62:959-970.
Schobert E (1987) Telazol use in wild and exotic animals. Vet Med 10:1080-1088.

Shima K, Aya K, Mushiake H, Inase M, Aizawa H, Tanji J (1991) Two movement-related foci in the primate cingulate cortex observed in signal-triggered and self-paced forelimb movements. J Neurophysiol 65:188-202.

Smith AM (1979) The activity of supplementary motor area neurons during a maintained precision grip. Brain Res 172:315-327.

Sprague JM (1948) A study of motor cell localization in the spinal cord of the rhesus monkey. Am J Anat 82:1-26.

Sterling P, Kuypers HGJM (1968) Anatomical organization of the brachial spinal cord of the cat. III. The propriospinal connections. Brain Res 7:419-443.

Tanji J (1994) The supplementary motor area in the cerebral cortex. Neurosci Res 19:251-268.

Tanji J, Kurata K (1979) Neuronal activity in the cortical supplementary motor area related with distal and proximal forelimb movements. Neurosci Lett 12:201-206.

Toyoshima K, Sakai H (1982) Exact cortical extent of the origin of the corticospinal tract (CST) and the quantitative contribution to the CST in different cytoarchitectonic areas. A study with horseradish peroxidase in the monkey. J Hirnforsch 23:257-269.

Weiller C, Ramsay SC, Wise RJS, Friston KJ, Frackowiak RSJ (1993) Individual patterns of functional reorganization in the human cerebral cortex after capsular infarction. Ann Neurol 33:181-189.

Wiesendanger M, Seguin JJ, Künzle H (1973) The supplementary motor area- a control system for posture. In: Control of posture and locomotion (Stein RB, Pearson KB, Smith RS, Redford JB, eds), pp 331-346. New York: Plenum.

Woolsey CN, Settlage PH, Meyer DR, Sencer W, Hamuy TP, Travis AM (1952) Patterns of localization in precentral and "supplementary" motor area and their relation to the concept of a premotor area. Assoc Res Nerv Ment Dis 30:238-264.

Yezierski RP, Gerhart KD, Schrock BJ, Willis WD (1983) A further examination of effects of cortical stimulation on primate spinothalamic tract cells. J Neurophysiol 49:424-441.

Zhang DX, Owens CM, Willis WD (1991) Short-latency excitatory postsynaptic potentials are evoked in primate spinothalamic tract neurons by corticospinal tract volleys. Pain 45:197-201. 